\title{
Prevalence and Determinants of Anemia among Children in Zanzibar, Tanzania: Analysis of Cross-Sectional Population Representative Surveys
}

\author{
Fatma Ally Said ${ }^{1,2}$, Ahmed Gharib Khamis ${ }^{3}{ }^{\mathbb{D}}$, Amanat Habib ${ }^{1} \mathbb{C}$, Hexiang Yang ${ }^{1}$, Zhangya He ${ }^{1}$ \\ and Xiaoqin Luo ${ }^{1, *}$ \\ 1 Department of Nutrition and Food Safety, School of Public Health, Xi'an Jiaotong University, \\ Xi'an 710061, China; datuu67@yahoo.com (F.A.S.); amanathabib@yahoo.com (A.H.); \\ clyeah@hotmail.com (H.Y.); hzy1129185047@stu.xjtu.edu.cn (Z.H.) \\ 2 Department of Preventive Services and Health Promotion, Ministry of Health Zanzibar, Zanzibar, Tanzania \\ 3 Department of Epidemiology and Biostatics, Muhimbili University of Health and Allied Science, \\ Dar-es-salaam, Tanzania; ahmadboycd@gmail.com \\ * Correspondence: luoxiaoqin2012@mail.xjtu.edu.cn; Tel.: +86-29-8265-5470
}

Citation: Said, F.A.; Khamis, A.G.; Habib, A.; Yang, H.; He, Z.; Luo, X. Prevalence and Determinants of Anemia among Children in Zanzibar, Tanzania: Analysis of Cross-Sectional Population Representative Surveys. Children 2021, 8, 1091. https:// doi.org/10.3390/children8121091

Academic Editor: Marek Ussowicz

Received: 21 September 2021

Accepted: 19 November 2021

Published: 25 November 2021

Publisher's Note: MDPI stays neutral with regard to jurisdictional claims in published maps and institutional affiliations.

Copyright: (c) 2021 by the authors. Licensee MDPI, Basel, Switzerland. This article is an open access article distributed under the terms and conditions of the Creative Commons Attribution (CC BY) license (https:/ / creativecommons.org/licenses/by/ $4.0 /)$.

\begin{abstract}
The aim of this study was to assess the prevalence of anemia and its determinants among children aged 6-59 months in Zanzibar, Tanzania, from 2005 to 2015. We used secondary data from the Tanzania Demographic and Health Surveys from three different periods: 2005, 2010, and 2015. A sample of 3502 child-mother pairs from three survey datasets was used to analyze the overall prevalence of anemia and reveal its determinants. Hierarchical logistic regression was used to demonstrate the prevalence odds ratio of factors, both from the mothers and children, for anemia prevalence. The study indicated a significant decrease in anemia prevalence from $76.1 \%$ in 2005 to $65.4 \%$ in 2015 ( $p$ 0.001). Hierarchical logistic regression between variables and anemia showed a significant association ( $p=0.02$ ) with households that improperly disposed of stool, children with minimum dietary diversity $(p=0.041)$, children in low age quartiles $(p=<0.001)$, and underweight children $(p=0.025)$. Maternal, household characteristics, and child factors were associated with childhood anemia in Zanzibar, Tanzania. Despite the significant decrease of anemia in Zanzibar, the overall prevalence rate is still a significant public health concern. Designing and strengthening comprehensive interventions to address anemia in the general population and different categories should be given special consideration.
\end{abstract}

Keywords: anemia; prevalence; determinants; children; Zanzibar; Tanzania

\section{Introduction}

Anemia is a global public health problem affecting one-third of the world's population both in developed and developing countries, with significant consequences for human health as well as for social and economic development [1,2]. Anemia is a condition defined as a considerable reduction of hemoglobin concentration or reduction of circulating red blood cells below the normal range, making it insufficient to meet an individual's physiological needs [3-5].

Though anemia affects people of all ages, pregnant women and children are more affected. It was estimated that $42 \%$ of children less than five years of age and $40 \%$ of pregnant women are anemic globally. It is a significant public health problem associated with increased morbidity and mortality in women and children [6-8], poor birth outcomes [9], decreased work productivity in adults [10], and impaired cognitive and behavioral development in children [11]. The most significant contributor to the onset of anemia is iron deficiency due to insufficient iron intake through diet, iron mal-absorption or elevated demand for iron due to abrupt growth $[12,13]$. It was reported that $50 \%$ of the cases of 
anemia have iron deficiencies but more often in coexistence with a variety of other causes that can be isolated [14].

According to the anemia regional disparities report, one-third of the Tanzanian population is anemic, and Zanzibar reported a slight reduction in childhood anemia prevalence of nearly $10 \%$ [15]. However, the overall situation needs to be observed as Tanzania Demographic and Health Surveys concluded that $65 \%$ of children under 5 were anemic in Zanzibar [16]. Over the years, Tanzania has been struggling and has made tremendous economic transformations that have decreased the underlying form of malnutrition. However, Zanzibar, a autonomous country in the United Republic of Tanzania, is still suffering from a high prevalence of anemia in children, 15 points more than that of mainland Tanzania [15]. In addition, information on anemia determining factors other than those related to iron deficiency is minimal. The current study was carried out to establish information on the trend of anemia prevalence and mainly its determinants in children between 6-59 months in Zanzibar to be used by the policymakers and nutrition practitioners.

\section{Materials and Methods}

\subsection{Study Design}

The secondary data analysis utilized three Tanzania Demographic and Health Surveys (TDHS) conducted in 2005, 2010, and 2015, available from the online portal of demographic health programs (www.dhsprogram.com, access date: 16 January 2020). These national representative surveys employ cross-sectional study designs to measure levels, patterns and trends in demographic and health indicators and are conducted every five years in all regions of mainland Tanzania and Zanzibar, by the National Bureau of Statistics (NBS) in mainland Tanzania and the Office of the Chief Government Statistician (OCGS) in Zanzibar.

We analyzed three datasets, TDHS 2005, 2010, and 2015, to determine the prevalence of anemia in children because they have the variables needed for the analysis, and the data was collected in a similar manner [16]. The three datasets were only used for analysis to determine the prevalence and only the TDHS dataset of 2015 was used to determine the correlation of anemia in children, aiming to avoid missing variables across three data sets. The three data sets used for analysis had a total sample of 3502 child-mother pairs and of them 1147 were from 2005, 1182 were from 2010, and 1173 were from 2015.

\subsection{Dependent Variable}

The primary outcome of interest was anemia. In all three TDHS surveys, anemia was measured as hemoglobin $(\mathrm{Hb})$ concentration in the blood. Blood samples were drawn from a drop of blood taken from a finger prick and collected in a micro cuvette. $\mathrm{Hb}$ level analysis was carried out on-site using a battery-operated portable Hemo-Cueanalyzer, and results were obtained on the spot. The cutoff points of anemia in TDHS were less than $110 \mathrm{~g} / \mathrm{L}$ according to the cut off points for anemia recommended by WHO.

\subsection{Independent Variables}

Independent variables included child age in months, child's sex, birth weight in grams, feeding practices of the children, diarrhea, fever, vitamin A supplementation, iron supplementation, deworming, and anthropometric indices (stunting, wasting, and underweight). Other independent variables were the caregiver's educational level, maternal anemia, number of children living in the house, maternal age, residence and wealth index, sex, and age of the head of the household. The anthropometric measurements were taken using a standard weighing scale and height board.

\subsection{Data Analysis}

Analysis of data was done using SPSS (IBM Version 23.0, SPSS Inc., Chicago, IL, USA). Descriptive statistics were used to describe the characteristics of the study population. We used Pearson Chi-square tests to compare the prevalence of anemia between three years and between ages categories, where we used age quartiles to decrease the bias. 
A hierarchical regression model was used to determine factors associated with anemia. The association was measured using the recent survey dataset of 2015, aiming to avoid missing variables across the three surveys. Variables were categorized into three models: household factor as the first model, with a $p$-value $>0.005$, maternal factors as the second model, which had a $p$-value $>0.005$, and child factors as the third model.

Association between dependent and independent variables was determined using odds ratios (OR) at $p<0.05$ with a $95 \%$ confidence interval.

\section{Results}

\subsection{Descriptive Characteristics of the Children, 2005-2015}

Results revealed that more than $70 \%$ of the interviewed households were from rural areas in all three surveys. The proportion of interviewed households in rural areas was $82.2 \%, 75.2 \%$, and $81.0 \%$ in 2005, 2010, and 2015, respectively. The respondents' wealth index showed that $35.6 \%, 32.0 \%$, and $38.4 \%$ of the respondents in 2005, 2010, and 2015, respectively, were richer. Each survey showed that the richer group of respondents were older than any other group. There was an increase in maternal educational attainment at the level of secondary education, which was $37.1 \%$ in 2005 and improved to $50.0 \%$ in 2015. More than $90 \%$ of the mother respondents were married, and more than $80 \%$ of the households were male-headed. In all three datasets, most of the interviewed households had between 4 and 10 people in their households. Meanwhile, anemia decreased with the increasing wealth index of the respondents ( $p$ for tend $=0.004$ ) and anemia also decreased with an increasing BMI of the mother respondents ( $p$ for tend $=0.01$ ) $($ Table 1$)$.

Table 1. Descriptive characteristics of the respondents, 2005-2015.

\begin{tabular}{|c|c|c|c|c|c|c|}
\hline \multirow[b]{2}{*}{ Variables } & \multicolumn{2}{|c|}{2005} & \multicolumn{2}{|c|}{2010} & \multicolumn{2}{|c|}{2015} \\
\hline & $\begin{array}{c}\text { Anemia } \\
\text { N (\%) }\end{array}$ & $\begin{array}{c}\text { No Anemia } \\
\text { N (\%) }\end{array}$ & $\begin{array}{c}\text { Anemia } \\
\text { N (\%) }\end{array}$ & $\begin{array}{c}\text { No Anema N } \\
(\%)\end{array}$ & $\begin{array}{c}\text { Anemia N } \\
(\%)\end{array}$ & $\begin{array}{c}\text { No Anemia } \\
\text { N (\%) }\end{array}$ \\
\hline \multicolumn{7}{|c|}{ Residence of the respondent } \\
\hline Urban & $153(75)$ & $51(25)$ & $198(67.6)$ & $95(32.4)$ & $141(63.6)$ & $80(36.2)$ \\
\hline Rural & $719(76.2)$ & $224(23.8)$ & $632(71.1)$ & $257(28.9)$ & $638(67)$ & $314(33.0)$ \\
\hline \multicolumn{7}{|c|}{ Wealth index of the respondents $(p$ for tend $=0.004$ ) } \\
\hline Poorest & $85(83.3)$ & $17(16.7)$ & $52(74.3)$ & $18(25.7)$ & $11(84.6)$ & $2(15.4)$ \\
\hline Poorer & $92(74.8)$ & $31(25.2)$ & $127(71.8)$ & $50(28.2)$ & $88(73.3)$ & $32(26.7)$ \\
\hline Middle & $149(79.3)$ & $39(20.7)$ & $146(71.2)$ & $59(28.8)$ & $148(70.1)$ & $63(29.9)$ \\
\hline Richer & $307(75.2)$ & $101(24.8)$ & $276(72.4)$ & $105(27.6)$ & $311(69.0)$ & $140(31.0)$ \\
\hline Richest & $239(73.3)$ & $87(26.7)$ & $229(65.6)$ & $120(34.4)$ & $221(58.5)$ & $157(41.5)$ \\
\hline \multicolumn{7}{|c|}{ The educational level of the mother respondents } \\
\hline No education & $298(76.8)$ & $90(23.2)$ & $218(71.7)$ & $86(28.3)$ & $198(72.3)$ & $75(27.7)$ \\
\hline Primary & $314(75.8)$ & $100(24.2)$ & $300(69.4)$ & $132(30.6)$ & $198(67.1)$ & $97(32.9)$ \\
\hline Secondary & $240(76.2)$ & $75(23.8)$ & $308(70.2)$ & $131(29.8)$ & $376(63.9)$ & $212(36.1)$ \\
\hline Higher & $20(66.7)$ & $10(33.3)$ & $4(57.1)$ & $3(42.9)$ & $9(47.4)$ & $10(52.6)$ \\
\hline \multicolumn{7}{|c|}{ Marital status of the respondent } \\
\hline Single & $7(87.5)$ & $1(12.5)$ & $9(90.0)$ & $1(10)$ & $10(100)$ & $0(0)$ \\
\hline Married/with partner & $807(75.8)$ & $257(24.2)$ & $768(69.8)$ & $332(30.2)$ & $707(65.8)$ & $368(34.2)$ \\
\hline Separated/Divorced & $58(77.3)$ & $17(22.7)$ & $53(73.6)$ & $19(26.4)$ & $62(70.5)$ & $26(29.5)$ \\
\hline \multicolumn{7}{|c|}{ Sex of Head of household } \\
\hline Male & $767(76.3)$ & $238(23.7)$ & $726(70.8)$ & $300(29.2)$ & $683(67.3)$ & $332(32.7)$ \\
\hline Female & $105(73.9)$ & $37(26.1)$ & $104(66.7)$ & $52(33.3)$ & $96(60.8)$ & $62(39.2)$ \\
\hline \multicolumn{7}{|c|}{ BMI of the mother respondent $\left(\mathrm{kg} / \mathrm{m}^{2}\right)(p$ for tend $=0.01)$} \\
\hline Underweight & $133(77.3)$ & $39(22.7)$ & $94(75.2)$ & $31(24.8)$ & $68(72.3)$ & $26(27.7)$ \\
\hline Normal & $557(77.3)$ & $164(22.7)$ & $474(72.4)$ & $181(27.6)$ & $406(69.8)$ & $176(30.2)$ \\
\hline Overweight & $120(74.5)$ & $41(25.5)$ & $184(66.7)$ & $92(33.3)$ & $184(63.4)$ & $106(36.6)$ \\
\hline Obesity & $62(66.7)$ & $31(33.3)$ & $78(61.9)$ & $48(38.1)$ & $121(58.5)$ & $86(41.5)$ \\
\hline \multicolumn{7}{|c|}{ Number of people living in the house } \\
\hline 3 and below & $72(76.6)$ & $22(23.4)$ & $59(72.0)$ & $23(28.0)$ & $59(72.0)$ & $23(28.0)$ \\
\hline 4 to 10 & $746(76.7)$ & $226(23.3)$ & $702(70.3)$ & $296(29.7)$ & $645(64.8)$ & $350(35.2)$ \\
\hline above 10 & $54(66.7)$ & $27(33.3)$ & $69(67.6)$ & $33(32.4)$ & 75 (78.1) & $21(21.9)$ \\
\hline
\end{tabular}




\subsection{The Trend in the Prevalence of Anemia among 6-59-Month-Old Children in Zanzibar}

As shown in Table 2, the prevalence of anemia decreased significantly over 15 years, from $76.1 \%$ in 2005 to $65.4 \%$ in 2015 ( $p$-value $<0.001$ ), almost $10 \%$.

Table 2. Trends in prevalence of anemia among 6-59-month-old children Zanzibar (2005-2015).

\begin{tabular}{ccc}
\hline Year & Anemia & $p$-Value for Trend \\
\hline 2005 & 76.1 & \\
2010 & 70.2 & 0.001 \\
2015 & 65.4 & \\
\hline
\end{tabular}

\subsection{Prevalence of Childhood Anemia Adjusted between Ages}

The prevalence rate was high in the low age quartile across all surveys. Among 1147 individuals interviewed in 2005, the prevalence of anemia was high, $29.2 \%$ in the Q1 age group, and the least was $21.4 \%$ in the Q4 age group. In 2010, 30.9\% of the anemic children were in the Q1 age group, while $20.1 \%$ were in the Q4 age group. In 2015, 33.4\% of the anemic children were in the Q1 age group and the least, $18.1 \%$, in the Q4 age group. The rate of anemia was revealed to be high in the Q1 age group across all surveys (Table 3 ).

Table 3. Prevalence of childhood anemia adjusted between ages in Zanzibar 2005-2015.

\begin{tabular}{|c|c|c|c|c|c|c|}
\hline \multirow[t]{2}{*}{ Age Quartiles } & \multicolumn{2}{|c|}{$\begin{array}{c}2005 \\
n=1147 \\
\text { Anemia }(n=872)\end{array}$} & \multicolumn{2}{|c|}{$\begin{array}{c}2010 \\
n=1182 \\
\text { Anemia }(n=830)\end{array}$} & \multicolumn{2}{|c|}{$\begin{array}{c}2015 \\
n=1173 \\
\text { Anemia }(n=779)\end{array}$} \\
\hline & $n(\%)$ & $p$-Value & $n(\%)$ & $p$-Value & $n(\%)$ & $p$-Value \\
\hline Q1 & $255(29.2)$ & \multirow{4}{*}{$<0.001$} & $257(30.9)$ & \multirow{4}{*}{$<0.001$} & $260(33.4)$ & \multirow{4}{*}{$<0.001$} \\
\hline Q2 & $234(26.8)$ & & 227 (27.3) & & $203(26.1)$ & \\
\hline Q3 & $196(22.5)$ & & $176(21.5)$ & & 175 (22.5) & \\
\hline Q4 & 187 (21.4) & & $167(20.1)$ & & 141 (18.1) & \\
\hline
\end{tabular}

\subsection{The Association of Household Characteristics and Maternal Characteristics with Anemia among Children}

Table 4 shows the results of hierarchical logistic regression analysis of anemia. The results reveal that households that improperly disposed of stool were at risk of getting anemia ( $a \beta=1.44,95 \%$ CI: $1.06-1.94, p=0.02)$, compared to households with a proper stool disposal system. No other household and maternal factors were revealed to have an association with childhood anemia.

Table 4. Hierarchical regression analysis of the association of household characteristics and maternal characteristics with anemia among children aged 6 to 59 months in Zanzibar, Tanzania.

\begin{tabular}{|c|c|c|c|c|c|}
\hline \multirow{2}{*}{\multicolumn{2}{|c|}{ Variables }} & \multicolumn{2}{|c|}{ Crude Odds Ratio (COR) } & \multicolumn{2}{|c|}{ Adjusted Odds Ratio (AOR) } \\
\hline & & \multirow[t]{2}{*}{ COR $(95 \% \mathrm{CI})$} & \multirow[t]{2}{*}{$p$-Value } & \multirow[t]{2}{*}{ AOR $(95 \% \mathrm{CI})$} & \multirow[t]{2}{*}{$p$-Value } \\
\hline \multirow{2}{*}{\multicolumn{6}{|c|}{\begin{tabular}{lr}
\multicolumn{2}{c}{ Household Characteristics } \\
Residence
\end{tabular}}} \\
\hline & & & & & \\
\hline \multirow{3}{*}{ Gender of $\mathrm{HHH}$} & Rural & $1.15(0.85-1.56)$ & 0.362 & $0.80(0.56-1.13)$ & 0.216 \\
\hline & Male & Ref & & Ref & \\
\hline & Female & $0.75(0.53-1.06)$ & 0.107 & $0.78(0.55-1.12)$ & 0.187 \\
\hline \multirow{3}{*}{$\begin{array}{c}\text { Age of the } \mathrm{HHH} \\
\text { (years) }\end{array}$} & $18-29$ & Ref & & Ref & \\
\hline & $30-49$ & $0.72(0.47-1.1)$ & 0.131 & $0.82(0.53-1.26)$ & 0.373 \\
\hline & $\geq 50$ & $0.73(0.47-1.16)$ & 0.186 & $0.92(0.57-1.47)$ & 0.741 \\
\hline \multirow{5}{*}{ Household wealth } & Middle & Ref & & Ref & \\
\hline & Poorest & $2.34(0.51-1.87)$ & 0.277 & $2.64(0.53-1.29)$ & 0.233 \\
\hline & Poorer & $1.17(0.71-1.93)$ & 0.537 & $1.2(0.70-2.10)$ & 0.503 \\
\hline & Richer & $0.94(0.66-1.35)$ & 0.758 & $1.03(0.69-1.54)$ & 0.863 \\
\hline & Richest & $0.59(0.41-0.86)$ & 0.005 & $0.76(0.47-1.21)$ & 0.252 \\
\hline
\end{tabular}


Table 4. Cont.

\begin{tabular}{|c|c|c|c|c|c|}
\hline \multirow{2}{*}{\multicolumn{2}{|c|}{ Variables }} & \multicolumn{2}{|c|}{ Crude Odds Ratio (COR) } & \multicolumn{2}{|c|}{ Adjusted Odds Ratio (AOR) } \\
\hline & & \multirow{2}{*}{$\frac{\operatorname{COR}(95 \% \mathrm{CI})}{\operatorname{Ref}}$} & \multirow[t]{2}{*}{$p$-Value } & \multirow{2}{*}{$\frac{\text { AOR }(95 \% \mathrm{CI})}{\text { Ref }}$} & \multirow[t]{2}{*}{$p$-Value } \\
\hline $\begin{array}{l}\text { Presence of } \\
\text { iodized salt }\end{array}$ & Yes & & & & \\
\hline \multirow[t]{2}{*}{ Stool disposal } & $\begin{array}{c}\text { No } \\
\text { Properly disposed }\end{array}$ & $\begin{array}{c}0.69(0.53-0.91) \\
\text { Ref }\end{array}$ & 0.008 & $\begin{array}{c}1.43(0.55-3.71) \\
\text { Ref }\end{array}$ & 0.455 \\
\hline & $\begin{array}{c}\text { Improperly } \\
\text { disposed }\end{array}$ & $1.53(1.15-2.05)$ & 0.004 & $1.44(1.06-1.94)$ & 0.020 \\
\hline Water sources & $\begin{array}{l}\text { Protected } \\
\text { Unprotected }\end{array}$ & $\begin{array}{c}\text { Ref } \\
1.18(0.53-2.62)\end{array}$ & 0.674 & $\begin{array}{c}\text { Ref } \\
1.22(0.54-2.75)\end{array}$ & 0.632 \\
\hline \multicolumn{6}{|c|}{ Mother Characteristics } \\
\hline Mother's BMI & $\begin{array}{l}\text { Underweight } \\
\text { Normal } \\
\text { Overweight } \\
\text { Obesity }\end{array}$ & $\begin{array}{c}\text { Ref } \\
0.88(0.54-1.43) \\
0.66(0.39-1.11) \\
0.54(0.32-0.91)\end{array}$ & $\begin{array}{l}0.612 \\
0.116 \\
0.022\end{array}$ & $\begin{array}{c}\text { Ref } \\
0.97(0.58-1.64) \\
0.88(0.51-1.52) \\
0.79(0.45-1.41)\end{array}$ & $\begin{array}{l}0.938 \\
0.646 \\
0.431\end{array}$ \\
\hline \multirow[t]{2}{*}{$\begin{array}{l}\text { Age of mother } \\
\text { (years) }\end{array}$} & $<18$ & Ref & & Ref & \\
\hline & $\begin{array}{c}18-35 \\
>35\end{array}$ & $\begin{array}{l}0.60(0.43-0.84) \\
0.53(0.35-0.82)\end{array}$ & $\begin{array}{l}0.003 \\
0.004\end{array}$ & $\begin{array}{l}0.83(0.57-1.21) \\
0.87(0.53-1.45)\end{array}$ & $\begin{array}{l}0.332 \\
0.608\end{array}$ \\
\hline \multirow[t]{2}{*}{$\begin{array}{l}\text { Mother's } \\
\text { occupation }\end{array}$} & Not working & Ref & & Ref & \\
\hline & $\begin{array}{c}\text { Self-employment } \\
\text { Farmers } \\
\text { Employed }\end{array}$ & $\begin{array}{l}0.93(0.59-1.46) \\
1.08(0.66-1.77) \\
0.66(0.51-0.87)\end{array}$ & $\begin{array}{l}0.764 \\
0.762 \\
0.003\end{array}$ & $\begin{array}{l}0.94(0.58-1.53) \\
1.27(0.74-2.17) \\
0.81(0.61-1.09)\end{array}$ & $\begin{array}{l}0.832 \\
0.384 \\
0.174\end{array}$ \\
\hline \multirow{2}{*}{$\begin{array}{l}\text { Education of } \\
\text { mother }\end{array}$} & No education & Ref & & Ref & \\
\hline & $\begin{array}{l}\text { Primary } \\
\text { Secondary } \\
\text { Higher }\end{array}$ & $\begin{array}{l}0.78(0.54-1.12) \\
0.68(0.49-0.93) \\
0.34(0.13-0.88)\end{array}$ & $\begin{array}{l}0.179 \\
0.016 \\
0.026\end{array}$ & $\begin{array}{l}0.85(0.58-1.26) \\
0.88(0.60-1.28) \\
0.48(1.77-1.35)\end{array}$ & $\begin{array}{l}0.435 \\
0.496 \\
0.167\end{array}$ \\
\hline
\end{tabular}

HHH, Household Head.

\subsection{The Association of Child Characteristics with Anemia among Children}

We finally analyzed the association of children's characteristics with anemia (Table 5). It was revealed that children in the lower age quartile were found to be more likely to have anemia ( $\mathrm{\beta} \beta=0.18,95 \%$ CI: $0.12-0.28, p<0.001)$ and $(\mathrm{a} \beta=0.30,95 \%$ CI: $0.20-0.44, p<0.001$ ), and those children with minimum dietary diversity (MDD) were more likely to have anemia $(a \beta=0.61, C I=0.37-0.98, p=0.045)$ compared to their counterparts. Underweight children were also at higher risk of having anemia ( $\alpha=1.54,95 \%$ CI: $0.94-2.52, p=0.025)$.

Table 5. Hierarchical regression analysis of the association of child characteristics with anemia among children aged 6 to 59 months in Zanzibar, Tanzania, based on the TDHS 2015.

\begin{tabular}{|c|c|c|c|c|c|}
\hline \multirow{2}{*}{\multicolumn{2}{|c|}{ Variables }} & \multicolumn{2}{|c|}{ Crude Odds Ratio (COR) } & \multicolumn{2}{|c|}{ Adjusted Odds Ratio (AOR) } \\
\hline & & COR $(95 \% \mathrm{CI})$ & $p$-Value & AOR $(95 \% \mathrm{CI})$ & $p$-Value \\
\hline \multicolumn{6}{|c|}{ Child Characteristics } \\
\hline \multirow[t]{4}{*}{$\begin{array}{l}\text { Age of child } \\
\text { (months) }\end{array}$} & Q1 & Ref & & Ref & \\
\hline & Q2 & $0.73(0.43-1.24)$ & 0.250 & $0.18(0.12-0.28)$ & $<0.001$ \\
\hline & Q3 & $0.35(0.21-0.58)$ & $<0.001$ & $0.30(0.20-0.44)$ & $<0.001$ \\
\hline & $\widehat{\mathrm{Q}} 4$ & $0.19(0.12-0.31)$ & $<0.001$ & $0.87(0.66-1.13)$ & 0.02 \\
\hline \multirow[t]{2}{*}{ Gender of child } & Male & Ref & & Ref & \\
\hline & Female & $0.92(0.72-1.17)$ & 0.52 & $0.84(0.64-1.09)$ & 0.195 \\
\hline \multirow{2}{*}{$\begin{array}{l}\text { Birth weight } \\
\text { (grams) }\end{array}$} & Above $2500 \mathrm{~g}$ & Ref & & Ref & \\
\hline & Below $2500 \mathrm{~g}$ & $1.24(0.69-2.21)$ & 0.461 & $1.16(0.62-2.17)$ & 0.352 \\
\hline \multirow[t]{2}{*}{ Place of delivery } & Health facility & Ref & & Ref & \\
\hline & At home & $1.06(0.83-1.36)$ & 0.622 & $0.95(0.57-1.60)$ & 0.863 \\
\hline
\end{tabular}


Table 5. Cont.

\begin{tabular}{|c|c|c|c|c|c|}
\hline \multirow{2}{*}{\multicolumn{2}{|c|}{ Variables }} & \multicolumn{2}{|c|}{ Crude Odds Ratio (COR) } & \multicolumn{2}{|c|}{ Adjusted Odds Ratio (AOR) } \\
\hline & & \multirow{2}{*}{$\frac{\text { COR }(95 \% \mathrm{CI})}{\operatorname{Ref}}$} & \multirow[t]{2}{*}{$p$-Value } & \multirow{2}{*}{$\frac{\text { AOR }(95 \% \mathrm{CI})}{\text { Ref }}$} & \multirow[t]{2}{*}{$p$-Value } \\
\hline Diarrhea & No & & & & \\
\hline \multirow{3}{*}{ Symptoms of fever } & Yes & $1.45(0.97-2.16)$ & 0.065 & $0.85(0.55-1.33)$ & 0.486 \\
\hline & No & Ref & & Ref & \\
\hline & Yes & $1.24(0.89-1.72)$ & 0.188 & $1.13(0.79-1.62)$ & 0.485 \\
\hline \multirow{3}{*}{$\begin{array}{c}\text { Initiation of } \\
\text { breastfeeding }\end{array}$} & Within an hour & Ref & & Ref & \\
\hline & After an hour & $1.43(1.03-1.99)$ & 0.032 & $1.43(0.98-2.05)$ & 0.058 \\
\hline & After one day & $0.72(0.54-0.96)$ & 0.025 & $1.0(0.63-1.58)$ & 0.988 \\
\hline \multirow[t]{2}{*}{ MDD } & No & Ref & & Ref & \\
\hline & Yes & $1.0(0.71-1.41)$ & 0.985 & $0.61(0.37-0.98)$ & 0.045 \\
\hline \multirow[t]{2}{*}{ MMF } & No & Ref & & Ref & \\
\hline & Yes & $2.66(1.75-4.03)$ & $<0.001$ & $0.89(0.49-1.63)$ & 0.719 \\
\hline \multirow[t]{2}{*}{ MAD } & No & Ref & & Ref & \\
\hline & Yes & $2.5(1.14-5.36)$ & 0.021 & $1.88(0.68-5.20)$ & 0.224 \\
\hline \multirow[t]{2}{*}{ Deworming } & No & Ref & & Ref & \\
\hline & Yes & $0.74(0.57-0.95)$ & 0.020 & $1.14(0.85-1.55)$ & 0.377 \\
\hline \multirow[t]{2}{*}{ Iron-rich food } & No & Ref & & Ref & \\
\hline & Yes & $1.55(1.21-2.00)$ & 0.001 & $1.18(0.82-1.69)$ & 0.375 \\
\hline \multirow[t]{2}{*}{ Stunting } & No & Ref & & Ref & \\
\hline & Yes & $1.26(0.95-1.67)$ & 0.116 & $0.96(0.67-1.36)$ & 0.815 \\
\hline \multirow[t]{2}{*}{ Wasting } & No & Ref & & Ref & \\
\hline & Yes & $1.56(0.93-2.63)$ & 0.094 & $0.91(0.48-1.71)$ & 0.768 \\
\hline \multirow[t]{2}{*}{ Underweight } & No & Ref & & Ref & \\
\hline & Yes & $1.81(1.24-2.63)$ & 0.002 & $1.54(0.94-2.52)$ & 0.025 \\
\hline
\end{tabular}

MDD, minimum dietary diversity; MMF, minimum meal frequency; MAD, minimum acceptable diet.

\section{Discussion}

Childhood anemia is still a public health threat in Zanzibar. The findings showed that the overall prevalence of anemia is $65.4 \%$, and the prevalence of anemia decreased significantly over 15 years, from $76.1 \%$ in 2005 to $65.4 \%$. The prevalence rate was high in the low age quartile. There is a positive association between anemia and households with improperly disposed stool, children with minimum dietary diversity, children in low age quartiles, and underweight children.

The reported prevalence is similar to the national reported prevalence of $65 \%$ [16]. This prevalence was found to decrease when compared with the prevalence of 2005, which was $74.1 \%$. The higher prevalence was very similar to the prevalence reported in the three districts of the Arusha region with 84.6\% [17] and the Mwanza region with 77.2\% [18]. It has been reported that children are fed with staple foods rich in carbohydrates like rice, maize, and cassava as the main meal and fail to incorperate iron-rich food in their meal [15]. In accordance with a previous study [19], our results also indicated that inappropriate feeding practices, which lead to nutritional inadequacy, influence the reported anemic prevalence in Zanzibar. The reported prevalence was also influenced by poverty, as it was highlighted that most forms of undernutrition continue to persist in Zanzibar, with children from impoverished households being three times more at risk. Again, there were some gaps in the provision of nutrition services. For example, less than $10 \%$ of women took iron supplements during pregnancy [20], contributing to child anemia after delivery. This was consistent with the reported high prevalence of maternal anemia in Zanzibar of $43.2 \%$ [21].

The burden of child anemia has significantly declined for the past fifteen years from 74.1 to $65.0 \%$. It was undoubtedly due to improved health care services and increased deworming coverage to over $90 \%$ in under-five children across all Zanzibar [22]. However, the malaria prevalence rate decreasing to less than $1 \%$ [16] contributed greatly to this notable reduction of anemia prevalence in children. Despite this significant decline, the 
anemia prevalence was still high and unacceptable, which may affect the intellectual capacity of children.

The analysis also revealed the disparities of prevalence rates in different age quartiles. The prevalence among young children was higher than that of all other age groups across all years. This situation was likely due to inappropriate feeding practices that lead to an insufficient daily intake of iron by children [23], as it was reported that in Zanzibar, only $18 \%$ of children receive diversified food and those with a minimum acceptable diet is reported to be less than 30\% [21]. Early initiation of complementary food, inadequate breastfeeding, and susceptibility to infection affect essential micro-nutrients bioavailability from the diet consumed by Zanzibar children [19]. The findings were very similar to a survey done in Ethiopia, Ghana, and Bangladesh [24-26].

Our study revealed the association between anemia and households which dispose of stool improperly, children in the low age quartile, those with MDD, and those underweight. The likelihood of developing anemia was significantly associated with households that improperly disposed of stool, and this might be due to the exposure of helminth infections from stool that can contribute to the likelihood of anemia occurrence in children [27]. It has been claimed that most households have improper sewage systems, and there is no centralized sewage system in Zanzibar [28]. Households reported to have no toilet is $16 \%$, with more than $30 \%$ reported to have inadequate toilet facilities in Zanzibar [29].

The children's age was significantly associated with anemia; younger children were more at risk than the older ones. The results showed that those in low-age quartiles had increased risk. The observed association may be due to poor feeding practices, early weaning, inadequate breastfeeding, and susceptibility to infection. A report that was written by Kinabo et al., in 2012, showed that there were problems of early weaning in children in Zanzibar, as the mean age of the weaning period was 4 months. There was also a lack of knowledge on the best complementary feeding practices in mothers [19]. The report insisted that the problem was due to a lack of awareness and limited information on child feeding. It was also about the poor food preparation and feeding skills, thus solidifying why younger children are at more risk of developing anemia [21].

The results showed a strong correlation between anemia and MDD, while MDD was associated with anemia in children due to inadequate food diversification. Although Zanzibar has a wide variety of local foods suitable for feeding children, in this study, only $18 \%$ had a MDD. In addition, mothers/caregivers lacked knowledge of how best to combine these foods to prepare energy- and nutrient-dense diets [19,21]. A number of reports have documented inappropriate skills of mothers in preparing complementary food and feeding practices as well $[16,21,28]$.

Among the analyzed variables related to children, low weight for age (underweight) remained associated positively with anemia. Many other factors contributed to the association of anthropometric indices and anemia, including poverty, water, and sanitation. As reported, there is a flawed centralized sewage system in Zanzibar and no sanitary policies and caring practices with food insecurity [20]. This report was highlighted in Zanzibar's nutrition policy and insisted that women did most agricultural activities with limited potential for crop and livestock production. In addition, there is negligible diversification of income-generating activities as most of the Zanzibar area is prone to environmental degradation, and their households are highly vulnerable to acute, chronic, and transitory food insecurity and malnutrition [28]. This observed association was also reported in other studies [30-32].

This study clarifies the prevalence of childhood anemia in Zanzibar, Tanzania, over 15 years, with some limitations to consider. The analysis of prevalence and trends included three surveys, and correlations were identified only from the most recent surveys and so older surveys may show different correlations compared to the most recent ones. However, the recent survey was used to avoid missing information on some variables that determine this association. Despite the above limitation, this study will provide insight into trends 
regarding anemia and will hopefully provide a clue on possible critical interventions for children in Zanzibar.

\section{Conclusions}

Anemia in children aged 6-59 months decreased across the years, but this improvement was still not convincing, and the higher rate was found in lower age categories. Lower age, underweight, given MDD, and improper stool disposal were associated with childhood anemia in Zanzibar. Special interventions, such as improving the addition of iron-rich foods, vitamin $C$ supplementation to children, supporting deworming programs, and community promotion on good feeding practices with food diversification should be given serious consideration to address this problem.

Author Contributions: F.A.S. analyzed the data, interpreted the results and drafted the manuscript. A.H., H.Y., and Z.H. participated in analysis and was the major contributor in writing the manuscript. A.G.K. performed the data analysis and prepared the tables. X.L. designed the study, compiled and reviewed the manuscript, and contributed to writing. All authors have read and agreed to the published version of the manuscript.

Funding: This research received no external funding.

Institutional Review Board Statement: The use of these datasets with data analysis protocol was approved by the Zanzibar Medical Research Ethical Committee (ZAMREC), the National Institute of Medical Research (NIMR), the Institutional Review Board of ICF International, and the Centers for Disease Control and Prevention in Atlanta. Since we used secondary data, individual consent was not required, and no personal identity was identified from the data.

Informed Consent Statement: Not applicable.

Data Availability Statement: The data for this study is available upon request from the TDHS portal (www.dhsprogram.com, access date: 16 January 2020).

Acknowledgments: We would like to acknowledge www.dhsprogram.com (access date: 16 January 2020) for giving us access to all datasets.

Conflicts of Interest: The authors declare no conflict of interest.

Patient Consent for Publication: Not required.

Consent for Publication: Not applicable for this study.

\section{References}

1. World Health Organization. Worldwide Prevalence of Anaemia 1993-2005: WHO Global Database on Anaemia; de Benoist, B., McLean, E., Egli, I., Cogswell, M., Eds.; WHO Press: Geneva, Switzerland, 2008; p. 40. ISBN 9789241596657.

2. Kassebaum, N.J.; Jasrasaria, R.; Naghavi, M.; Wulf, S.K.; Johns, N.; Lozano, R.; Regan, M.; Weatherall, D.; Chou, D.P.; Eisele, T.P.; et al. A Systematic Analysis of Global Anemia Burden from 1990 to 2010. Blood 2014, 123, 615-624. [CrossRef]

3. Sanou, D.; Ngnie-Teta, I. Risk Factors for Anemia in Preschool Children in Sub-Saharan Africa; IntechOpen: London, UK, 2012; ISBN 978-953-51-0138-3.

4. World Health Organization. Haemoglobin Concentrations for the Diagnosis of Anaemia and Assessment of Severity; World Health Organization: Geneva, Switzerland, 2011; p. 6.

5. Gebreweld, A.; Ali, N.; Ali, R.; Fisha, T. Prevalence of Anemia and Its Associated Factors among Children under Five Years of Age Attending at Guguftu Health Center, South Wollo, Northeast Ethiopia. PLoS ONE 2019, 14, e0218961. [CrossRef]

6. Soewondo, S.; Husaini, M.; Pollitt, E. Effects of Iron Deficiency on Attention and Learning Processes in Preschool Children: Bandung, Indonesia. Am. J. Clin. Nutr. 1989, 50, 667-674. [CrossRef]

7. Basta, S.S.; Soekirman; Karyadi, D.; Scrimshaw, N.S. Iron Deficiency Anemia and the Productivity of Adult Males in Indonesia. Am. J. Clin. Nutr. 1979, 32, 916-925. [CrossRef]

8. Scott, S.; Chen-Edinboro, L.; Caulfield, L.; Murray-Kolb, L. The Impact of Anemia on Child Mortality: An Updated Review. Nutrients 2014, 6, 5915-5932. [CrossRef] [PubMed]

9. Rasmussen, K.M. Is There a Causal Relationship between Iron Deficiency or Iron-Deficiency Anemia and Weight at Birth, Length of Gestation and Perinatal Mortality? J. Nutr. 2001, 131, 590S-603S. [CrossRef] [PubMed]

10. Haas, J.D.; Brownlie, T. Iron Deficiency and Reduced Work Capacity: A Critical Review of the Research to Determine a Causal Relationship. J. Nutr. 2001, 131, 676S-690S. [CrossRef] 
11. Walker, S.P.; Wachs, T.D.; Meeks Gardner, J.; Lozoff, B.; Wasserman, G.A.; Pollitt, E.; Carter, J.A. Child Development: Risk Factors for Adverse Outcomes in Developing Countries. Lancet 2007, 369, 145-157. [CrossRef]

12. Woldie, H.; Kebede, Y.; Tariku, A. Factors Associated with Anemia among Children Aged 6-23 Months Attending Growth Monitoring at Tsitsika Health Center, Wag-Himra Zone, Northeast Ethiopia. J. Nutr. Metab. 2015, 2015, 1-9. [CrossRef] [PubMed]

13. Saaka, M. Relationship between Dietary Diversity and Haematological Status of Children Aged 6-59 Months in Northern Ghana. J. Nutr. Health Sci. 2017, 1, 1-23.

14. FAO; UNICEF; WHO; WFP; IFAD. The State of Food Security and Nutrition in the World 2018: Building Climate Resilience for Food Security and Nutrition; Food \& Agriculture Organization: Rome, Italy, 2018; ISBN 978-92-5-130571-3.

15. Sunguya, B.F.; Zhu, S.; Paulo, L.S.; Ntoga, B.; Abdallah, F.; Assey, V.; Mpembeni, R.; Huang, J. Regional Disparities in the Decline of Anemia and Remaining Challenges among Children in Tanzania: Analyses of the Tanzania Demographic and Health Survey 2004-2015. Int. J. Environ. Res. Public. Health 2020, 17, 3492. [CrossRef]

16. Ministry of Health, Community Development, Gender, Elderly and Children/Dar es Salaam; Ministry of Health/Zanzibar; National Bureau of Statistics-/Dar es Salaam; Office of Chief Government Statistician- /Zanzibar; ICF/Rockville, Maryland, USA. Tanzania Demographic and Health Survey and Malaria Indicator Survey 2015-2016. 2016. Available online: https: / / dhsprogram.com/publications/publication-fr321-dhs-final-reports.cfm (accessed on 16 January 2020).

17. Kejo, D.; Petrucka, P.M.; Martin, H.; Kimanya, M.E.; Mosha, T.C. Prevalence and Predictors of Anemia among Children under 5 Years of Age in Arusha District, Tanzania. Pediatr. Health Med. Ther. 2018, 9, 9-15. [CrossRef] [PubMed]

18. Simbauranga, R.H.; Kamugisha, E.; Hokororo, A.; Kidenya, B.R.; Makani, J. Prevalence and Factors Associated with Severe Anaemia amongst Under-Five Children Hospitalized at Bugando Medical Centre, Mwanza, Tanzania. BMC Hematol. 2015, 15, 13. [CrossRef] [PubMed]

19. Kinabo, J.; Mamiro, P.; Mwanri, A.; Bundala, N.; Msuya, J.; Ntwenya, J.; Kulwa, K.; Nombo, A.; Mzimbiri, R.; Macha, E.; et al. Assessment of Infant and Young Children Feeding Practices in Zanzibar Using the Process for the Promotion of Child Feeding (ProPAN) Tool. Ann. Nutr. Metab. 2013, 63, 35-36.

20. Revolutionary Government of Zanzibar. The Zanzibar Strategy for Growth and Reduction of Poverty: $2010-2015$ (ZSGRP II): MKUZA II.; Revolutionary Government of Zanzibar: Zanzibar City, Tanzania, 2010; p. 198.

21. Tanzania; Ofisi ya Taifa ya Takwimu; Shirika la Chakula Bora Tanzania. Tanzania National Nutrition Survey 2018: Final Report; University of Dodoma, Development Partners and UNICEF: Dodoma, Tanzania, 2019.

22. Ministry of Health, Zanzibar, Tanzania. Health Information System. Available online: www.mohzn.go.tz (accessed on 5 August 2021).

23. Rashid, M.; Flora, M.S.; Moni, M.A.; Akhter, A.; Mahmud, Z. Reviewing Anemia and Iron Folic Acid Supplementation Program in Bangladesh-A Special Article. Bangladesh Med. J. 2010, 39. [CrossRef]

24. Ewusie, J.E.; Ahiadeke, C.; Beyene, J.; Hamid, J.S. Prevalence of Anemia among Under-5 Children in the Ghanaian Population: Estimates from the Ghana Demographic and Health Survey. BMC Public Health 2014, 14, 626. [CrossRef] [PubMed]

25. Desalegn, A.; Mossie, A.; Gedefaw, L. Nutritional Iron Deficiency Anemia: Magnitude and Its Predictors among School Age Children, Southwest Ethiopia: A Community Based Cross-Sectional Study. PLoS ONE 2014, 9, e114059. [CrossRef]

26. Rahman, M.S.; Mushfiquee, M.; Masud, M.S.; Howlader, T. Association between Malnutrition and Anemia in Under-Five Children and Women of Reproductive Age: Evidence from Bangladesh Demographic and Health Survey 2011. PLoS ONE 2019, 14, e0219170. [CrossRef]

27. Ngesa, O.; Mwambi, H. Prevalence and Risk Factors of Anaemia among Children Aged between 6 Months and 14 Years in Kenya. PLoS ONE 2014, 9, e113756. [CrossRef]

28. Revolutionary Government of Zanzibar. Policy-Zanzibar Food Security and Nutrition Policy I Global Database on the Implementation of Nutrition Action (GINA); Revolutionary Government of Zanzibar: Zanzibar, Tanzania, 2008.

29. Office of the Chief Government Statistician, Zanzibar. Zanzibar Household Budget Survey 2014/15; Office of the Chief of Government Statistician: Zanzibar, Tanzania, 2016.

30. Leite, M.S.; Cardoso, A.M.; Coimbra, C.E.; Welch, J.R.; Gugelmin, S.A.; Lira, P.C.I.; Horta, B.L.; Santos, R.V.; Escobar, A.L. Prevalence of Anemia and Associated Factors among Indigenous Children in Brazil: Results from the First National Survey of Indigenous People's Health and Nutrition. Nutr. J. 2013, 12, 69. [CrossRef]

31. Mohammed, S.H.; Habtewold, T.D.; Esmaillzadeh, A. Household, Maternal, and Child Related Determinants of Hemoglobin Levels of Ethiopian Children: Hierarchical Regression Analysis. BMC Pediatr. 2019, 19, 113. [CrossRef] [PubMed]

32. Yang, W.; Li, X.; Li, Y.; Zhang, S.; Liu, L.; Wang, X.; Li, W. Anemia, Malnutrition and Their Correlations with Socio-Demographic Characteristics and Feeding Practices among Infants Aged 0-18 Months in Rural Areas of Shaanxi Province in Northwestern China: A Cross-Sectional Study. BMC Public Health 2012, 12, 1127. [CrossRef] [PubMed] 